\title{
GRUPOS ARTÍSTICO-LITERARIOS EN LA VENEZUELA DE LOS AÑOS SESENTA
}

Carmen Virginia Carrillo*

\begin{abstract}
RESUMEN: En este artículo se describe la evolución de Sardio (1958), Tabla Redonda (1959) y El Techo de la Ballena (1961) los grupos artístico-literarios más importantes surgidos en Venezuela, en los años sesenta. Se analizan las pugnas que los enfrentaron, los alcances de sus planteamientos y la participación que tuvieron en los procesos de transformación del campo literario venezolano de esta década.
\end{abstract}

PalABRAS CLAVE: Grupos artísticos-literarios, Renovación, Venezuela.

ABSTRACT: This article describes the evolution of Sardio, Tabla redonda and El techo de la ballena, the most important artistic-literary groups to arise in the sixties. The struggles between them are analyzed, the scope of their statements and the participation they had in the transformation process of the literary field of Venezuela on that decade.

KEY WORDS: Artistic and literary groups, Renovation, Venezuela.

En Venezuela, la década del sesenta podría considerarse la más fecunda en cuanto a grupos artístico-literarios se refiere. Tanto en la capital como en el interior del país, los jóvenes intelectuales se cohesionaban atendiendo a intereses estético-ideológicos, en la mayoría de los casos de izquierda y de carácter abiertamente subversivo.

En el presente trabajo describiremos la evolución de los tres grupos más importantes, Sardio (1958), Tabla Redonda (1959) y El Techo de la Ballena (1961), las pugnas que los enfrentaron y los alcances de sus planteamientos, así como también la participación que tuvieron en los procesos de transformación del campo literario venezolano en la década del sesenta.

*Universidad de los Andes. Núcleo Trujillo (cvct@ula.ve). 


\section{SARDIO}

El año de 1958, con la publicación del primer número de la revista homónima, puede señalarse como la fecha oficial del inicio de Sardio. Sin embargo sus integrantes ya conformaban un grupo coherente desde 1955. Venidos de todas las regiones del país para cursar el último año de bachillerato, la mayoría de los jóvenes que integraron el grupo coincidieron en el liceo Fermín Toro, otros ya habían comenzado sus estudios en la Universidad Central. Les unían inquietudes artísticas e ideológicas y el gusto por la bohemia. En 1957, abrieron una galería-librería en donde realizaron exposiciones y conferencias, este espacio se transformó en punto de reunión de escritores, artistas plásticos y gente de cine. Sardio auspiciaba la integración de las artes.

En el primer comité de redacción de la revista se encontraban Adriano González León, Guillermo Sucre, Rómulo Aranguibel, Rodolfo Izaguirre y Luis García Morales; en el número 3-4 se integraron Gonzalo Castellanos, Elisa Lerner, Salvador Garmendia y Ramón Palomares. Participaron también Francisco Pérez Perdomo, Carlos Contramaestre, Edmundo Aray, Pedro Duno, Efraín Hurtado, Caupolicán Ovalles, Elizabeth Schön y los pintores Manuel Quintana Castillo, Perán Erminy, Mateo Manaure, Marcos Miliani y Omar Carreño.

Políticamente sus miembros se agruparon en torno a una concepción social demócrata, aunque algunos de ellos eran de izquierda. Siguiendo la línea de pensamiento de Jean Paul Sartre, se consideraban afiliados a un humanismo político de izquierda. ${ }^{1}$ Declararon un compromiso activo con la cultura y el país, y asumieron una actitud contestataria. Insistían en recalcar el espíritu polémico que los animaba y su intención de llevar al pueblo una educación racional y democrática.

\footnotetext{
${ }^{1}$ Entre los autores más leídos por los integrantes del grupo Sardio se encontraba Sartre; las ideas del filósofo francés fueron fundamentales para la concepción ideológica del grupo. Sartre defiende el llamado "humanismo existencialista" en su texto El existencialismo es un humanismo (1985). El filósofo apela a una "moral de la libertad" idea fundamental en la ideología de Sardio.
} 
El grupo se define y expone su ideario en cinco textos programáticos llamados "Testimonios", en ellos los integrantes de Sardio dirigieron un ataque directo a los valores burgueses, no exento de contradicciones respecto a sus prácticas. En el primer "Testimonio", publicado en el número inicial de la revista, de mayo-junio 1958, se sientan las bases del compromiso que, frente a las circunstancias históricas que vivía el país, y frente al arte y la cultura, perciben los sardianos:

Ante el peso de una historia singularmente preñada de inminencias angustiosas, como la de nuestros días, ningún hombre de pensamiento puede eludir esa militancia sin traicionar su propia, radical condición. Las hasta hace poco imperantes categorías del esteticismo resultan hoy demasiado estrechas y asépticas. Ser artista implica tanto una voluntad de estilo y un ejercicio del alma como una reciedumbre moral y un compromiso ante la vida. ${ }^{2}$

A lo largo del texto los autores describen los elementos del arte y la cultura que rechazan y proponen otros como indispensables para la reconstrucción del espacio cultural nacional, en la nueva coyuntura política de la naciente democracia. Los sardianos rechazaban la postura idealista para resolver los problemas, de ahí que considerasen que ser artista "implica tanto una voluntad de estilo y un ejercicio del alma, como una reciedumbre moral y un compromiso con la vida". ${ }^{3}$ Resaltaban la necesidad de que los intelectuales asumieran una postura crítica, polémica y orientadora. La libertad era considerada el más importante de los valores, "suprema aspiración universal de nuestro tiempo" tanto en lo artístico, como en lo político y lo económico.

En el ámbito literario condenaron el esteticismo, el nacionalismo exacerbado y arrogante, la anécdota, el paisajismo y la visión pintoresca de la realidad. A su vez rechazaron la literatura "de esquemas y soluciones preconcebidas", 4 en su lugar propusieron una concepción universalista de lo nacional, una visión y una sensibilidad nuevas.

\footnotetext{
2 “Testimonio", Sardio, núm. 1, Caracas, mayo-junio, 1958, p. 1.

${ }^{3}$ Loc. cit.

${ }^{4}$ Ibid., p. 3.
} 
En el número 2 de Sardio, firmado por el Comité de Redacción el 8 de septiembre de 1958, aparece el segundo "Testimonio" titulado "Ante la grave situación política del país”, en el texto, los autores marcan su posición en relación a un acontecimiento de represión ocurrido en el país. El tercer "Testimonio" titulado "Las constantes de nuestra generación", se publica en los números 5-6 de la revista, de enero - abril de 1959; en este documento el grupo se defiende de la crítica que los ha calificado de "sectarios, elitescos o aristocratizantes" y se define como:

una generación consciente de su destino, poseída por una voluntad de trascendencia, fiel a las verdaderas y dramáticas constantes del tiempo que le ha tocado vivir y en él enraizada y comprometida, [...] un grupo de escritores y artistas para quienes la creación es combate con el destino o con la historia". ${ }^{5}$

Tras cuestionar el oportunismo político de algunos intelectuales, insisten en lo que consideran el "único imperativo del espíritu: una vasta y penetrante comunicación con el universo, los sueños, la grandeza y aun la miseria del hombre". ${ }^{6}$ Ofrecen un saludo esperanzador a la Revolución cubana y repudian la visita del vicepresidente norteamericano, Richard Nixon.

El cuarto "Testimonio", "El intelectual de izquierda y cierta estética revolucionaria”, aparece en el séptimo número. Los autores del texto comienzan con el debate sobre la necesidad de compromiso que tiene el escritor o el intelectual con la ideología y la sociedad, tanto en su obra como en su actividad cotidiana. Luego analizan el compromiso del intelectual de izquierda y hacen un llamado de atención a aquellos escritores que traicionan su verdadera vocación al dejarse enajenar por lineamientos ideológicos e imposiciones políticas, lo que, dicen, conduce a la mediocridad inventiva. Los sardianos reiteran la concepción del escritor como demiurgo que prevalece en los textos programáticos

5 “Las constantes de nuestra generación”, Sardio, núms. 5-6, Caracas, enero-abril, 1959, p. 277.

${ }^{6}$ Ibid., p. 279. 
del grupo, rechazan el realismo socialista por considerarlo una "estética sin grandeza y estereotipada" y recuerdan que:

El acto de crear consiste, en última instancia, en rehacer un universo en el que la criatura humana tenga infinitas relaciones y secretas e inagotables posibilidades, liberadas del amargo determinismo de la simple causalidad; en el que todas las grandes y pequeñas pasiones del hombre, sus oscuros anhelos y frustradas esperanzas, sus sueños, su instinto y su inteligencia, revelen un sentido de devenir, de incesante cambio y transfiguración, como la propia vida. ${ }^{7}$

El último de los testimonios titulado "Testimonio sobre Cuba" aparece en el octavo y último número de la revista, en mayo-junio de 1961. Los redactores de este polémico número fueron Gonzalo Castellanos, Rodolfo Izaguirre y Edmundo Aray. La aparición de este texto, junto con el pre-manifiesto de El Techo de la Ballena publicado al final de la revista, marcó la escisión del grupo. Guillermo Sucre, Luis García Morales y Elisa Lerner, los más comprometidos con el partido de gobierno, Acción Democrática, rechazaron la adhesión manifiesta con el proceso cubano y se distanciaron. Los más cercanos a la izquierda pasaron al grupo que recién se anunciaba.

En el "Testimonio sobre Cuba", que aparece sin firma, su redactor hace un análisis exhaustivo del conflicto entre Cuba y Estados Unidos y critica la actitud imperialista del gobierno norteamericano. Finaliza este "Testimonio" con las siguientes palabras:

Finalmente no vacilamos en declarar a la revolución cubana como un anticipo de la REVOLUCIÓN IRREMEDIABLE, pues, ya no se trata de un cambio en los métodos, sino de un vuelco radical del ser humano a la conquista de otras maneras y otras relaciones y vínculos que establecerán las bases de un nuevo lenguaje, de una nueva vida que preparará, mientras se espera el advenimiento de la sociedad sin clase. ${ }^{8}$

7“"El intelectual de izquierda y cierta estética revolucionaria”, Sardio, núm. 7, Caracas, abril-mayo, 1960, pp. 433-434.

8 “Testimonio sobre Cuba”, Sardio, año III, vol. VI, núm. 8, Caracas, mayo-junio, 1961, p. 16. 
Además de la revista, Sardio edita, distribuye y, en oportunidades, vende directamente las obras de sus integrantes, así como también la obra traducida de escritores de otras latitudes, particularmente autores franceses. Las actividades editoriales de estos grupos fue una constante en la década del sesenta, de esta manera los jóvenes escritores lograron establecer pequeños circuitos de distribución que les permitieron formar un público lector. Entre los libros editados por Sardio se encuentran: Las hogueras más altas (1957) de Adriano González León, El reino (1958) de Ramón Palomares, Los pequeños seres (1959) de Salvador Garmendia, Fantasmas y enfermedades (1961) de Francisco Pérez Perdomo, Nadie quiere descansar (1961) de Edmundo Aray y Estrechos son los navíos de Saint John Perse, traducido por Guillermo Sucre.

Sardio se caracterizó por sus proposiciones renovadoras, su espíritu libertario y su carácter ecuménico. El grupo tenía, a la par de una serie de inquietudes artísticas y literarias, intereses de tipo socio-cultural. Algunos de sus integrantes se preocuparon por hacer una revisión de los valores culturales nacionales; entre ellos cabe destacar a Pedro Duno. Para el autor la incoherencia domina todas sus estructuras, por ello propone afianzar el espíritu nacional a través de la superación de los conflictos y la integración comunitaria como vías para alcanzar un auto-desarrollo que propicie la creación de una cultura original, objetiva y libre.

Algunos críticos, entre ellos Ángel Rama y Alfredo Chacón, han juzgado severamente al grupo. Indiscutiblemente el carácter tribal y cerrado que prevalecía en Sardio llevó a que se les tachara de elitistas y a que se les criticara el hecho de no haber podido lograr el papel de "estimuladores críticos de la conciencia cultural". ${ }^{9}$ Considera Chacón que el afán modernizador de Sardio no consiguió producir cambios culturales verdaderamente revolucionarios sino que, por el contrario, su afrancesamiento dio cuenta de una forma de mimetización que desvirtuó el verdadero compromiso y reafirmó nuestra dependencia cultural.

\footnotetext{
${ }^{9}$ Alfredo Chacón, La izquierda cultural venezolana 1958-1968, Caracas, editorial Domingo Fuentes, 1970, p. 53.
} 
La vinculación entre las artes que caracterizó al grupo forma parte de una tradición que se inicia con la asociación denominada El Círculo de Bellas Artes, de principios de siglo y que se continuó en los grupos artístico-literarios de los años sesenta.

Guillermo Sucre, Luis García Morales, Ramón Palomares, Francisco Pérez Perdomo y Edmundo Aray, iniciaron su actividad poética en Sardio. Elizabeth Schön (1921), la única poetisa del grupo, había publicado su primer libro, La gruta venidera, en 1953. En estos primeros poemas, escritos en prosa, percibimos la presencia de un discurso reflexivo, que busca en la filosofía la materia prima de su creación. De la década del sesenta son sus libros En el allá disparado desde ningún comienzo (1962) y El abuelo, la cesta y el mar (1965). En su segundo poemario la escritura de Schön cambia de rumbo hacia una poesía abstracta y en el siguiente libro da un nuevo giro, vuelve a la poesía en prosa y recrea el universo de los sentimientos.

Guillermo Sucre publica su primera obra, Mientras suceden los dias, el año de 1961. En los poemas, escritos en la década de los cincuenta, se dejan sentir las influencias de Saint-John Perce y Pablo Neruda. Los poemas nos hablan de las vivencias en el exilio, de ciudades extranjeras, de paisajes que se conectan afectivamente con la imagen de la mujer amada y memorias de la infancia. El tiempo es una de las principales preocupaciones del poeta. Nueve años más tarde publica La mirada (1970), libro que recoge los poemas escritos entre 1962 y 1969. El autor retoma el asunto amoroso y el exilio y amplía el espectro temático hacia la reflexión metapoética.

Luis García Morales (1929) tras publicar Lo real y la memoria (1962) se silenció hasta 1983, año en que edita su segundo libro de poemas, $E l$ río siempre. Una vez separado de Sardio ocupó importantes cargos en las instituciones culturales del Estado, convirtiéndose, con Juan Liscano y Guillermo Sucre, en los intelectuales más respetados del sistema.

Edmundo Aray (1936) ha explorado la narrativa, la cinematografía y la poesía, siendo más prolífero en este último género. La hija de Raghú (1957) fue su primer libro. En nadie quiere descansar (1961) publicado 
bajo el sello de Sardio, rememora el pasado y la mujer amada, exhorta a los jóvenes rebeldes a cambiar el mundo y se ocupa de la temática del individuo alineado por la urbe; asunto que retomará en el libro de relatos Sube para bajar (1963). Dos años más tarde, ya como miembro de $E l$ Techo de la Ballena, Aray se inicia en el ámbito de la literatura contestataria, de temática socio-política y carácter subversivo, que constituirá una de las líneas de su trabajo literario.

En Twist presidencial, "minimodramas", ${ }^{10}$ publicado en las ediciones tubulares, ${ }^{11}$ núm. 2, de El Techo de la Ballena, en agosto de 1963, la ironía desempeña un papel fundamental en el proceso de escritura. Tierra roja, Tierra negra (1968) su poemario más político, le hizo merecedor de una mención en el premio Casa de las Américas en 1968.

Ramón Palomares muestra, desde su primer poemario, El reino (1958), su particular sensibilidad por lo telúrico y por sus arraigos, característica que permanecerá como una marca a lo largo de toda su obra. Seis años más tarde aparece Paisano (1964). En 1975 el autor fue galardonado con el Premio Nacional de Poesía. Francisco Pérez Perdomo, y Elizabeth Schön recibieron el Premio Nacional de Literatura en los años 1980 y 1994, respectivamente; este reconocimiento constituye el más alto signo de consagración en el país.

En todos estos poetas percibimos un minucioso trabajo en el nivel del lenguaje, sin embargo cada uno dio a sus versos una orientación particular. La influencia surrealista se combina con la necesidad de dar una respuesta estético-ideológica novedosa a los procesos de transformación cultural que se estaban llevando a cabo en el país. Los poetas de Sardio proponen una representación de la realidad como espacio de contradicciones. A pesar de que sus integrantes se definen como iconoclastas en los

10 "Minimodramas" es la denominación que Edmundo Aray da a una serie de pequeñas piezas escritas en forma de diálogo.

${ }^{11}$ Las ediciones tubulares consistían en unos tubos de cartón de aproximadamente un metro de alto, forradas con textos, fotos o dibujos que se exponían en las galerías de El Techo de la Ballena. 
textos programáticos, el ideario se orienta hacia concepciones tradicionales del arte. Cabe resaltar la ética de compromiso que siempre destacó a los sardianos, siempre acorde con la orientación humanista del grupo.

\section{EL TECHO DE LA BALLENA}

En junio de 1961, el grupo Sardio se disuelve. Una semilla de insurgencia radical había comenzado a desarrollarse entre algunos de sus integrantes; aquellos que se identificaban con la Revolución cubana y con las ideologías de izquierda, pasaron a formar parte de El Techo de la Ballena, movimiento que había sido fundado por Carlos Contramaestre. Los escritores que se mantuvieron fieles a la ideología social demócrata, como Guillermo Sucre, Elisa Lerner y Luis García Morales, siguieron su trabajo literario en solitario y se incorporan a las instituciones culturales del Estado, tales como el diario La República, la Radio Nacional, la Revista Nacional de Cultura y el Instituto Nacional de Cultura y Bellas Artes (INCIBA), este último creado en 1965. Ramón Palomares no se integró al nuevo grupo, mas no ocupó cargos institucionales. Francisco Pérez Perdomo aunque pasó al INCIBA se unió a El Techo de la Ballena.

Las primeras publicaciones de El Techo de la Ballena aparecen en el último número de la revista Sardio, de mayo-junio, 1961, con tres textos que definían los intereses y las aspiraciones del grupo, un pre-manifiesto y las introducciones de los catálogos de las dos exposiciones que habían realizado en los meses de marzo y junio de ese mismo año. Los textos estaban antecedidos por una breve reseña del "Homenaje a la cursilería", en la que justificaban los móviles que les llevaron a realizar el evento: "la exposición que bajo el nombre de 'Homenaje a la cursilería' pudo revelar, a través de textos literarios de los más consagrados escritores nacionales, la aplastante superficialidad que limita y caracteriza la literatura venezolana". ${ }^{12}$

12 “Homenaje a la cursilería”, Sardio, año III, vol. VI, núm. 8, Caracas, mayo-junio, 1961, p. 136. 
El "Pre-manifiesto" comienza describiendo las intenciones del grupo y estableciendo cierta distancia con el dadaísmo y el surrealismo; tres años más tarde, en el texto “¿Por qué la Ballena?”, publicado en el Rayado sobre el Techo, ${ }^{13}$ núm. 3, los balleneros admitían la influencia que ejercieron en el grupo los movimientos vanguardistas europeos de principios de siglo, los Beat y la ideología de izquierda: "El Techo de la Ballena reconoce en las bases de su cargamento frecuentes y agresivos animales prestados a Dadá y al Surrealismo. Así como existen en sus vigas señales de esa avalancha acusadora de los poetas de California". ${ }^{14}$

Consideraban el absurdo y la burla como medios de expresión y calificaron de "trágico" al arte de su tiempo. El "Pre-manifiesto" finaliza con unas líneas de la imaginería ballenera y volcánica que configuran el universo simbólico-alegórico de El Techo de la Ballena:

[...]a fin de cuentas, lo que queremos es restituir el magma, la materia en ebullición, la lujuria de la lava. Demostrar que la ballena, para vivir, no necesita saber de zoología, pues toda vértebra tiene su riesgo, y ese riesgo, que todo acto creador incita, será la única aspiración de la ballena. Percibimos, a riesgo de asfixia, cómo los museos, las academias y las instituciones de cultura nos roban el pobre ozono y nos entregan a cambio un aire enrarecido y putrefacto. ${ }^{15}$

La idea de restitución de la materia ya aparece en el primer catálogo. El magma es visto como lo primigenio, lo arcaico, lo primordial, la génesis que hay que recuperar y a partir de lo que se construirá un mundo nuevo, libre de ataduras y convencionalismos limitantes. El magma y la ballena, lo ígneo y lo marino fusionados para violentar y renovar las estructuras artísticas tradicionales. La imagen del gran cetáceo irrumpiendo en el panorama cultural venezolano y asumiendo el riesgo del acto creador, responde a un acto fundacional que se lleva a cabo por la

${ }^{13}$ Rayado sobre el Techo constituye el órgano de difusión oficial del grupo.

14 “¿Por qué la Ballena?”, Sardio, año III, vol. VI, núm. 8, Caracas, mayo-junio, 1961, p. 137.

15 “Pre-manifiesto", Sardio, año III, vol. VI, núm. 8, Caracas, mayo-junio, 1961, p. 137. 
vía de la subversión. La misión que los balleneros se imponían era la de destruir las estructuras culturales y sociales alienadas y alienantes para luego "restituir el magma, la materia en ebullición, la prótesis de Adán", ${ }^{16}$ de ahí la agresividad de sus expresiones artísticas.

En la introducción al catálogo de la primera exposición, realizada en el mes de marzo de 1961 y titulada "Para restituir el magma", el magma aparece como alegoría del arte puro, sin procesar y, por ende, sin contaminar y es elevado a la máxima categoría artística; lo amorfo se carga de valor simbólico. Esta novedosa concepción de la materialidad artística se conecta con los postulados de los Informalistas españoles.

Es necesario restituir el magma la materia en ebullición la lujuria de la lava colocar una tela al pie de un volcán restituir el mundo la lujuria de la lava demostrar que la materia es más lúcida que el color de esta manera lo amorfo cercenado a la realidad todo lo superfluo que la impide trascenderse superar la inmediatez de la materia como medio de expresión haciéndola no instrumento ejecutor pero sí médium actuante que se vuelve estallido impacto la materia se trasciende la materia se trasciende las texturas se estremecen los ritmos tienden al vértigo eso que preside al acto de crear que es violentarse-dejar constancia de que se es porque hay que restituir al magma en su caída $[\ldots]^{17}$

Lo magmático está conectado con la lujuria, la trascendencia y lo arbitrario, tres de los elementos que se reiteran en las obras balleneras, tanto en la plástica, como en la literatura. En el texto, los espacios en blanco incrementan la indeterminación.

"Para la restitución del magma" junto con el manifiesto "El gran magma" constituyen los primeros textos programáticos del grupo, ambos publicados en el Rayado sobre el Techo, núm. 1, de marzo de 1961. "E1 gran magma" sigue la línea del anterior, tanto en su temática, como en su distribución espacial y en las relaciones que se establecen entre lo

16 “Para restituir el magma”, Sardio, año III, vol. VI, núm. 8, Caracas, mayo-junio, 1961, p. 137.

${ }^{17}$ Loc. cit. 
erótico y lo primigenio: “el techo de la ballena está fundado en la plena lucidez incontrolable del orgasmo que sólo los insomnios verifican porque la ballena es el único prisma válido es el único prisma que tiene su barbarie". ${ }^{18}$

En "El Segundo Manifiesto", aparecido en el Rayado sobre el Techo núm. 2, en mayo de 1963, El Techo de la Ballena se convierte en un "reo de putrefacción". En este texto se cuestiona la actitud de los artistas que aceptan premios oficiales. El párrafo final del manifiesto resume las propuestas estético-ideológicas del grupo: “El Techo de la Ballena cree necesario ratificar su militancia en una peripecia donde el artista y el hombre se jueguen su destino hasta el fin". ${ }^{19}$

Los balleneros se ubicaron en la periferia del campo literario, desde allí criticaron los cánones culturales existentes, subvirtieron los modelos en vigor y propusieron una ruptura herética que partía del retorno a los orígenes, como vía para alcanzar la pureza en el arte. Recién llegados al campo, rechazaron todos los signos sociales de consagración, tales como los premios y las representaciones, sin embargo, en la medida que estos escritores y artistas fueron afianzando su posición dentro del campo literario, formaron parte de la cultura, se dejaron arrastrar por el proceso de legitimación, cediendo a los reconocimientos académicos, sociales y oficiales.

El carácter contestatario de los manifiestos respondía a los cambios ideológicos que se produjeron a lo largo del continente. Su postura controversial les permitió demostrar la oposición a las estructuras de dominio y a las prohibiciones de tipo moral, religioso y político, y con ello desplazaron al público lector hacia zonas marginales. Desde ese espacio de la exclusión se apropiaron de un poder simbólico con el que confrontaron la autoridad.

El tercer y último manifiesto, titulado “¿Por qué la ballena?”, fue publicado en el Rayado sobre el Techo, núm. 3, en 1964. En los textos

${ }^{18}$ Juan Carlos Santaella, Manifiestos literarios venezolanos, Caracas, Monte Ávila, 1992, p. 73.

${ }^{19}$ Rayado sobre el Techo, núm. 2, Caracas, Ediciones del Techo de la Ballena, mayo, $1963, \mathrm{~s} / \mathrm{p}$. 
programáticos: Para la restitución del magma, El gran magma, El segundo manifiesto y ¿Por qué la Ballena?, se insiste en utilizar la transgresión como arma para hacer estallar la vida. La necesidad de ruptura con lo instituido encuentra un aliado en la expresión abyecta de un erotismo exacerbado. En estos textos las basuras, lo corrosivo y lo grotesco se convierten en parte fundamental de un universo discursivo que conlleva una gran carga de agresividad.

En sus integrantes se podía observar cierta actitud mesiánica. Intentaban desatar la polémica en el ámbito cultural, violentar al lector y al espectador de las exposiciones, escandalizarlo, desplazarlo hacia los espacios de la diferencia y la exclusión. Los artistas de El Techo preferían las zonas oscuras, lo obsceno y lo marginal; a estos elementos les atribuían un nuevo valor simbólico dentro del campo artístico. A partir de la liberación de las formas buscaban la transmutación de los valores establecidos.

La provocación fue una de las estrategias utilizadas por los balleneros. Este mecanismo era común en los otros movimientos neovanguardistas del continente; los Beat escandalizaban desde la década de los cincuenta a la sociedad norteamericana y los nadaístas hacían otro tanto con la burguesía católica colombiana. Ante el clima de violencia que predominaba en el planeta, las neovanguardias respondían violentando las convenciones, trastocando el sentido de lo estético.

Entre los escritores de El Techo de la Ballena se encontraban Adriano González León, Salvador Garmendia y Rodolfo Izaguirre en narrativa; Francisco Pérez Perdomo, Edmundo Aray, Caupolicán Ovalles y Efraín Hurtado en poesía. Entre los pintores cabe mencionar a Daniel González, Hugo Baptista, Perán Erminy, Manuel Quintana Castillo, Fernando Irazábal, Gabriel Morera, Jacobo Borges y Alberto Brandt. Juan Calzadilla y Carlos Contramaestre llevaron a cabo tanto actividades plásticas como literarias. El poeta chileno Dámaso Ogaz y el pintor catalán José M. Cruxent también se integraron al grupo.

En el ámbito de la plástica se adhirieron al informalismo, negaron el academicismo y el abstraccionismo geométrico, esta última tendencia era la dominante pictórica en la Venezuela de la década de los sesenta. 
Los balleneros rechazaban la institución museística y eligieron espacios alternativos para sus exposiciones, tales como los garajes-galerías por ellos fundados.

En el "Homenaje a la cursilería", para restablecer una frontera entre lo cursi y lo "pavoso" se expusieron los textos de los escritores venezolanos consagrados que, según los balleneros, eran de mal gusto. Pretendían, de esta manera, burlarse de la politiquería que dominaba al sector cultural. Para Ángel Rama la exposición “constituyó el primer intento de demolición de la concepción pequeño burguesa que dominaba a la cultura venezolana hasta el grado de impregnar no sólo sus manifestaciones oficiales sino también las opositoras". ${ }^{20}$ Sin embargo, el crítico Alfredo Chacón considera que este evento fue una "empresa ambigua, de muy limitado poder de crítica y venganza". ${ }^{21}$

El "Homenaje a la necrofilia" representó un acto de desafío social y político extremo. La agresividad de las piezas exhibidas, acompañadas de catálogos con textos virulentos, hizo estremecer a la opinión pública y desencadenó una serie de reacciones de repudio. Entre las más llamativas se encuentra la intervención de la Iglesia católica, que excomulgó a sus integrantes.

Una nota periodística anónima publicada en El Mundo el día 16 de noviembre del mismo año lleva por título: "Aberraciones eróticas difunde panfleto pornográfico hecho en la Universidad", y como subtítulo: "se exige al rector que explique quién autorizó la impresión". El 17 de noviembre, en el diario La Esfera se reseña el acontecimiento con el siguiente titular: "Nauseabundas aberraciones sexuales elogia folleto hecho en la Universidad" en el subtítulo se acusa al rector de la Universidad Central de Venezuela, De Venanzi, de complicidad por autorizar la impresión del "costoso panfleto de ponzoñosa e impía pornografía". 22 La interpretación que hace la prensa del "Homenaje a la necrofilia" es

\footnotetext{
20 Ángel Rama, Antología del Techo de la Ballena, Caracas, Fundarte, 1987, p. 12.

${ }^{21}$ Chacón, op. cit., p. 42.

22 "Nauseabundas aberraciones sexuales elogia folleto hecho en la Universidad", La Esfera de la Cultura, Caracas, 17 de noviembre, 1962.
} 
de carácter político; insiste en denunciar la orientación marxista comunista que se esconde tras el transgresor catálogo y su intención desestabilizadora del orden social.

La polémica sobre las propuestas de El Techo de la Ballena se siguió llevando a cabo en distintos periódicos nacionales. El objetivo se había alcanzado, el escándalo y el repudio de la sociedad se dejaban sentir en forma contundente, los balleneros habían llevado el arte más allá de lo admisible, habían profanado el espacio sagrado de la muerte.

La última exposición realizada por El Techo de la Ballena, el 30 de marzo de 1966, se llamó "La Ballena cierra el Techo"; sin embargo, en 1967 todavía realizaban actividades, y la más destacada fue el "Primer Encuentro Internacional de El Techo de la Ballena" (los meses de junio, julio y agosto).

En El Techo de la Ballena, arte y literatura se convirtieron en una forma de resistencia al poder. Lo escatológico, lo efímero y lo cotidiano se oponían a los cánones de belleza, trascendencia y legitimación artística. La experimentación, la exploración del horror, la transmutación y dispersión de los valores desdibujaban el principio de determinación estética.

Una de las características más resaltantes de El Techo de la Ballena fue su actitud iconoclasta. Los balleneros postulaban la subversión en el nivel estético y político y orientaban su producción artística hacia la elaboración de un discurso que buscaba sus fuentes en los modos de la ironía, la abyección, lo grotesco y la construcción de realidades alternas, procedimientos todos ellos muy carnavalescos.

Los escritores de El Techo de la Ballena rechazaban el realismo y el costumbrismo por considerarlos movimientos desgastados; la necesidad de sacudir al país del letargo cultural en el que había caído requería de un estilo más combativo en el que pudieran integrarse arte y vida. De la realidad seleccionaron el lado más oscuro y más violento. Para los integrantes de El Techo de la Ballena la agresión se convirtió en la forma de expresión de una literatura comprometida con un país en crisis. De esta manera, los balleneros sentían que se vinculaban a la lucha política, y contribuían al proceso subversivo. 
La actividad editorial fue una de las expresiones más importantes de este grupo. El equipo conformado por Edmundo Aray y Daniel González, con la colaboración eventual de Dámaso Ogaz, Adriano González León y Juan Calzadilla, se encargó de publicar las plaquettes, las ediciones tubulares, las postales con reproducciones de los artistas plásticos, diez poemarios, tres libros de narrativa y los tres números de la revista Rayado sobre el Techo. Estas publicaciones habitualmente iban acompañadas de ilustraciones de los pintores informalistas que eran parte del grupo o de grabados medievales de ballenas u otros monstruos marinos, lo que daba a los libros un carácter peculiar y novedoso. La última edición del grupo Salve, amigo, salve y adiós, salió al público el año de 1968, en ella participaron Edmundo Aray, Efraín Hurtado, Dámaso Ogaz, Juan Calzadilla, Carlos Contramaestre, Xavier Domingo, Marcia Leyseca y Tancredo Romero. Este trabajo marcó el fin de El Techo de la Ballena.

Las obras de los integrantes de El Techo de la Ballena publicadas bajo el sello del grupo son los libros de poesía ¿Duerme usted, señor presidente? (1962) y Elegía en rojo a la muerte de mi padre (1967) de Caupolicán Ovalles; Dictado por la jauría (1962), Malos modales (1965) y Las contradicciones sobrenaturales (1967) de Juan Calzadilla; Espada de doble filo (1962) y Los métodos y las deserciones imaginarias (1963 ) del poeta chileno Dámaso Ogaz y Los venenos fieles (1963) de Francisco Pérez Perdomo. El libro de textos narrativos de Adriano González León con fotos de Daniel González Asfalto-Infierno (1963), Sube para bajar (1963) de Edmundo Aray. En las particulares ediciones tubulares fueron publicados En uso de razón (1963) de Caupolicán Ovalles y Twist presidencial (1963) de Edmundo Aray. Editaron tres números de su revista: Rayado sobre el Techo; la primera en 1961, la segunda en 1963 y la tercera en 1964. Estas publicaciones contenían los manifiestos, textos en los que debatían sobre las polémicas que se establecían con otros intelectuales adversos al grupo, textos de creación de los integrantes y colaboraciones de escritores extranjeros.

Los escritores de El Techo de la Ballena preferían los géneros cortos, la poesía, el minimodrama, los cuentos. Entre los poetas, Caupolicán 
Ovalles y una línea del trabajo poético de Edmundo Aray, se encaminaron hacia la poesía subversiva, contestataria, de denuncia y estilo antipoético; Francisco Pérez Perdomo siguió la línea iniciada en Sardio con un lenguaje poético surrealizante en el cual lo onírico, la fantasmagoría y la dualidad son los ejes de articulación discursiva. Juan Calzadilla incursionó también en una poesía cercana al surrealismo con ciertas marcas de antipoesía y, en ocasiones, con algunos elementos de denuncia.

\section{TABLA REDONDA}

En el año 1959 surge el grupo Tabla Redonda formado por jóvenes intelectuales —en su mayoría poetas - militantes o simpatizantes del partido comunista: Jesús Sanoja Hernández (su fundador y principal animador), Arnaldo Acosta Bello, Rafael Cadenas, Jesús Enrique Guédez, Ángel Eduardo Acevedo, Oswaldo Barreto, Samuel Villegas, Mateo Manaure, José Fernández Doris, Manuel Caballero, Enrique Izaguirre y los pintores Darío Lancini y Ligia Olivieri. En la fase final se incorporaron Irma Salas, Dacha Nazoa y José Barroeta. El grupo, consecuente con su ideario político, desarrolló un persistente trabajo de apoyo a los grupo insurreccionales que se oponían al gobierno de Betancourt, lo que no significó que supeditaran el trabajo artístico y literario a los planteamientos ideológicos, por el contrario, la obra de la mayoría de los tablistas se manifestó al margen de los postulados políticos que en la práctica defendían.

Desde sus inicios Tabla Redonda asumió una postura de rechazo y crítica a las posturas estético-ideológicas del grupo Sardio a las que consideraban derechistas y reaccionarias. Esta pugna contribuyó con la radicalización de algunos de los miembros de Sardio hacia una izquierda más radical y a la inevitable división.

Al igual que en Sardio y El Techo de la Ballena, los escritores de Tabla Redonda estaban vinculados con artistas plásticos y desarrollaron una intensa actividad editorial. Publicaron una revista que llevaba el mismo nombre del grupo y se anunciaba como una publicación de 
"artes y letras" de circulación mensual; sin embargo entre mayo y diciembre de 1959 sólo fueron editados cuatro números. En el comité responsable del primer número de la revista se encontraban Arnaldo Acosta Bello, Rafael Cadenas, Manuel Caballero, Jesús Enrique Guédez, Jesús Sanoja Hernández y Darío Lancini. Este comité sufrió algunos cambios a lo largo de los diez números que aparecieron de la publicación.

Además de la revista, bajo el sello editorial del grupo se publicaron: Los cuadernos del destierro (1960) de Rafael Cadenas, Sacramentales (1961) y Sexantes (1965) de Jesús Enrique Guédez, Hechos (1965) de Arnaldo Acosta Bello (1927-1962), Príncipe caído príncipe de Samuel Villegas; así como la antología poética Ocho estaciones y el libro de cuentos Apagados y violentos (1964) de Jesús Alberto León.

Tabla Redonda realizó muy pocas actividades culturales, entre ellas, una exposición de poesía y pintura en 1964 y un recital de poesía en la Universidad Central de Venezuela. El interés del grupo se orientaba hacia la confrontación ideológica y al cuestionamiento del sistema a través de una actitud militante, de ahí que privilegiaran las polémicas y los textos ensayísticos.

Los integrantes de Tabla Redonda consideraban que la revisión del pasado cultural era fundamental para lograr el cambio en la sociedad, la principal preocupación del grupo era lograr una concienciación en el nivel ideológico. En la revista, dedicada sobre todo a temas nacionales, aparecen tanto textos de creación, como textos políticos de la izquierda venezolana; son usuales los trabajos sobre el compromiso intelectual y la justificación de la lucha armada.

Este grupo de escritores no se propuso la subversión como propuesta estética, su trabajo literario estaba más comprometido con la política que con la renovación poética, de ahí que se hiciera eco de las consideraciones de Mariátegui sobre el arte revolucionario en contraposición con el arte de la decadencia de corte nihilista y del planteamiento de que no todo lo nuevo en el arte es revolucionario.

Los planteamientos fundamentales del grupo se centraron en el compromiso de los intelectuales y la desmitificación del escritor como de- 
miurgo. A partir de estos dos núcleos de interés realizaron un cuestionamiento de la tradición artística nacional; sin embargo, y a diferencia de Sardio y El Techo de la Ballena, no buscaban una ruptura drástica con la herencia cultural; por el contrario, reconocían la necesidad de la continuidad del trabajo artístico. Así lo expresó Jesús Sanoja Hernández en un artículo titulado "Entre la loa y la destrucción" publicado en el número 4 de la revista:

Si algo dijimos los de Tabla Redonda desde un comienzo, era que no llegábamos en plan de "rebelión moral" y que creíamos en la continuidad del proceso artístico. Algún lenguaje excesivo o cierta descaminada tesis particular no pueden ser atribuidos a propósitos de destrucción negativa que conduzcan a la afirmación de una obra que todavía no hemos hecho. Son desajustes menores en el deseo mayor de enfrentarnos con lealtad a nuestros productos artísticos, a los que están por consagrarse o a los que algún día podrían hacerlo". ${ }^{23}$

Las divergencias de Tabla Redonda con Sardio y con El Techo de la Ballena se convirtieron en una polémica pública. El motivo de la primera confrontación que se llevó a cabo entre sardianos y tablistas lo constituyó un artículo que publicó Guillermo Sucre criticando a Pablo Neruda, a raíz de la visita del poeta chileno a Venezuela. En el número 3-4 de la revista Sardio del año 1958, Guillermo Sucre había escrito un artículo en el que cuestionaba el egocentrismo del poeta chileno y su obra.

Las réplicas por parte de Arnaldo Acosta Bello, Jesús Sanoja Hernández y Manuel Caballero aparecieron en los números 1 y 2 de Tabla Redonda. Sanoja Hernández cuestionó la estética y los trabajos literarios de los balleneros en sendos artículos aparecidos en los diarios El Clarín de los Viernes, y Arte y Letras de El Venezolano a los que replicaron Caupolicán Ovalles, Adriano González León y Edmundo Aray, este último en un texto aparecido en el Rayado sobre el Techo núm. 2 con el título 
de "Contra el arpón el mordisco de la ballena" de mayo de 1963. La polémica se inició a partir de un artículo publicado por Sanoja Hernández el 8 de marzo en el Clarín de los Viernes en el que comentaba el libro Arácnidas de Héctor Silva, el autor hace extensivo a El Techo de la Ballena su repudio a la estética de "la impureza y el asco", que predominaba en el libro de Silva.

En el texto "No basta la iracundia", publicado en El Clarín de los Viernes el 22 de marzo de 1963, Sanoja Hernández critica las propuestas balleneras en estos términos:

Y aquí surge nuestra objeción frontal a esa corriente de "la poesía nueva" y a algunos techistas sin fronteras: si hubiera que prestar la poesía o la pintura a un servicio circunstancial, provisorio, concebido como necesidad relativa y de momento ese préstamo no será por nuestra parte, a la iracundia. Será un préstamo a la violencia y a la guerra de conciencia actual, a la batalla civil, a la devastación creadora de esta Venezuela, en este punto de la historia, en este minuto, con este saldo de muertos y presos y consignas, ideas, manifestaciones guerrilleras, $[\ldots]^{24}$

La controversia se extendió por semanas; el acento de la discusión estaba puesto en las diferencias que, en el nivel de propuesta estético ideológicas, separaban a los dos grupos. Sanoja Hernández insistía en que el exceso de obscenidad e inmoralidad de las manifestaciones de El Techo de la Ballena llevaban al escándalo, pero perdían eficacia a la hora de acercarse a la realidad venezolana y el compromiso se diluía, mientras que Tabla Redonda consideraba que no era necesario utilizar estrategias anárquicas ni apelar a discursos poéticos irracionales para denunciar la violencia y lograr la transformación de las estructuras sociales.

Por su parte, el poeta y crítico Juan Liscano se convirtió en enemigo de Tabla Redonda, las diferencias ideológicas hicieron que el poeta y crítico se enfrentara, a través de la prensa, con los escritores de izquierda.

${ }^{24}$ Jesús Sanoja Hernández, "No basta la iracundia”, El Clarín de los Viernes, Caracas, 22 de marzo, 1963. 
Desde la columna de El Nacional, Liscano reseña el primer número de la revista en estos términos:

Tabla Redonda tiene que ser ubicada como publicación de partido. No se trata de una revista de ideas libres, sino de un instrumento de combate marxista para el marxismo. [...] "Tabla Redonda" no pretende afirmar una verdad de arte o de vida, sino un punto de vista marxista sobre la literatura y el pensamiento. [...] En el caso de "Tabla Redonda", aprecio la poesía de Sanoja, un viejo amigo de cuando "Cantaclaro", de Acosta Bello, de Guédez, de Cadenas. Todos ellos son buenos poetas. Estoy menos de acuerdo en su actitud polémica derivada de una toma de posición política. Sin duda alguna se corre el riesgo de mezclar literatura y política, ideología e ideas, consignas y pensamientos. Ese es el peligro real que acecha a "Tabla Redonda". 25

Desde la misma columna, Pedro Duno salió en defensa de Tabla Redonda y nuevamente replicó Liscano enfatizando su posición sobre la relación entre literatura y política:

Duno manifiesta que "literatura y política" se encuentran íntimamente conectadas y que no era de lamentar esa circunstancia como lo hacía yo, en relación con Tabla Redonda. Es verdad que siempre se tiene una actitud política, pero también es verdad que los marxistas no admiten una posibilidad de especulación literaria pura que, en función de su propio progreso y desarrollo, se justifique y cumpla. Yo si creo en esa posibilidad aunque toda mi obra sea ajena a la especulación literaria pura. Los marxistas sojuzgan la creación literaria a la consigna política — no digamos ideológica, lo cual quizás asfixiaría menos el arte- - Este es otro punto de oposición plena que tengo con el socialismo de Estado. ${ }^{26}$

El año de 1965 desaparece Tabla Redonda, si bien fue el grupo más radicalizado políticamente, sus integrantes no utilizaron la poesía como instrumento de adoctrinamiento, ni como arma de combate. En esta dé-

${ }^{25}$ Juan Liscano, "Tabla Redonda", Papel Literario de El Nacional, Caracas, 24 de septiembre, 1959 , p. 4.

${ }^{26}$ Juan Liscano, "Respuesta a Pedro Duno", Papel Literario de El Nacional, Caracas, 8 de octubre, 1959, p. 4. 
cada violenta, como ha sido denominada por la historiografía, unos optaron por llevar al arte la agresividad y la iracundia que vivían, mientras que otros prefirieron separar el compromiso vital de la obra literaria.

La poesía de Sanoja Hernández no es subversiva ni directa, por el contrario, es hermética y densa en el nivel metafórico; él mismo la ha calificado de "poesía metafísica". Para el autor, la poesía es un acto personal, individual, de ahí que no conciba la idea de plasmar la violencia del proceso revolucionario dentro de su mundo poético. En los poemas de su libro La mágica enfermedad se describe la fauna, la flora y se mencionan espacios de la geografía nacional: Caracas, el Orinoco, La Ceiba, Guayana, Falcón, la naturaleza es aclamada en todo su esplendor. En contraposición con la exuberancia del paisaje descrita en algunos de los poemas, en otros, se ofrece una visión negativa y alienante de la urbe. Esta representación del binomio ciudad-naturaleza se reitera, con algunas variantes, en la obra de varios poetas de la década.

Por su parte Arnaldo Acosta Bello, en su poemario Hechos (1965), asume un discurso poético directo, conciso e incluso áspero, para dejar constancia de la violencia que vive el país.

Rafael Cadenas (1930) es el poeta más importante de Tabla Redonda, y su obra ha sido considerada por la crítica como una de la más destacada del país en las últimas décadas. En 1960 Tabla Redonda editó el largo poema en prosa Los cuadernos del destierro; tres años más tarde apareció el poema más conocido de Cadenas, "Derrota", texto que plasma la crisis existencial de una generación que se sintió traicionada. El año 1966, la Universidad Central publicó Falsas maniobras, libro que agudiza la problematización del yo poético que ya se anunciaba en los textos anteriores.

De los grupos estudiados Sardio mantuvo una postura elitista y aburguesada. Tabla Redonda fue fiel a las líneas ideológicas de la izquierda extrema. El Techo de la Ballena puede considerarse el más transgresor, sus integrantes realizaron eventos al estilo dadaísta para escandalizar e insistieron en producir un cambio drástico tanto en las estructuras estéticas como en las sociales. 
Las posiciones políticas fueron determinantes en las valoraciones artísticas y generaron posturas encontradas de las que pocos lograron escapar. La mayoría de los grupos poéticos que surgieron a finales de los cincuenta y durante la década de los sesenta consideraban fundamental el compromiso político de los escritores; muchos de ellos llegaron incluso a producir obras de marcado cariz contestatario, otros, como Rafael Cadenas y Jesús Sanoja Hernández, lograron diferenciar la postura política de la creación poética. Una minoría se mantuvo al margen de la discusión ideológica, cabe mencionar entre ellos al poeta Eugenio Montejo.

En la medida en que las instituciones culturales del Estado abrieron sus puertas a los escritores de estos grupos, éstos pasaron a ocupar cargos en los diversos organismos, editoriales, revistas y universidades llegando incluso a ocupar cargos diplomáticos, como lo hicieron Adriano González León, Salvador Garmendia y Carlos Contramaestre, entre otros. Muchos de aquellos artistas y escritores, que en su momento representaron la insurgente vanguardia literaria, alcanzaron un sitial de honor en el proceso de legitimación oficial.

Recibido: julio de 2006 Aceptado: octubre de 2006 
